\title{
COMPARISON OF CHEMICAL COMPOSITION AND ANTIBACTERIAL ACTIVITY OF LAVENDER VARIETIES FROM POLAND
}

\section{(C) Adaszyńska Michalina, Swarcewicz Maria}

The West Pomeranian University of Technology, Szczecin, Department of Organic Synthesis and Drug Technology, Piastow Avenne 42, 71-065 Szczecin, Poland

The aim of the study was comparing the chemical composition of the essential oils from five varieties of lavender (Lavandula angustifolia L.) and their antibacterial activity. The flower spikes of different varieties of lavender comprised the material for the tests (Lavandula angustifolia): "Munstead", "Munstead Strain", "Blue River", "Ellegance Purple" and "Lavender Lady". The dried material parts $(20 \mathrm{~g})$ were submitted to hydrodistillation for 3 hours using Deryng's type apparatus, according to the European Pharmacopoeia. The oil was stored at $4{ }^{\circ} \mathrm{C}$ until the GC-MS analysis. The oils were assayed against three bacterial, Staphylococcus aureus, Pseudmonas aeruginosa and Escherichia coli. Evaluation of antimicrobial activity in vitro of the essential oil was performed with the use of the disc - diffusion method. 18 Hour cultivation of a particular strain of bacteria in liquid medium was diluted with physiological $\mathrm{NaCl}$ solution to a density of 0.5 McFarland. Obtained in this way, a bacterial suspension was applied evenly over the entire plate surface to a solid Mueller-Hinton II (Oxoid), using a sterile swab sticks. Paper disks (diameter
$6 \mathrm{~mm}$ ) were soaked with $10 \mu \mathrm{l}$ of a particular essential oil and were immediately applied symmetrically on the inoculated plate. Plates were incubated for $24 \mathrm{~h}$ at $37{ }^{\circ} \mathrm{C}$ and next zones of inhibition were measured. The primary components of the analyzed essential oils were: linalool $(23,9-15,8 \%)$, linalyl anthranilate (12,3-1,6\%), 1-terpinen-4-ol (9,7-5,5\%), p-menth1-en-8-ol (7,9-4,0\%), linalool oxide (4,7-1,1\%). Moreover, we observed a difference in some compounds, existing in low concentrations that may influence the biological properties. From the essential oils that were tested, the "Blue River" variety have the greatest antibacterial activity. The highest increase of Staphylococcus aureus as well as Pseudomonas aeruginosa and Escherichia coli bacteria was inhibited by the activity of the essential oils from the "Blue River" variety. Medium zones of inhibition for "Blue River" are as follows: $19.5 \mathrm{~mm}$ on Staphylococcus aureus (reference strain), $18.2 \mathrm{~mm}$ on Staphylococcus aureus (strain isolated from skin MRSA/ORSA), $10.0 \mathrm{~mm}$ on Pseudomonas aeruginosa (strain isolated from skin) and $19.9 \mathrm{~mm}$ on Escherichia coli (reference strain).

\section{CLINICAL TRIALS OF ORIGINAL PHYTOPREPARATIONS AND PROSPECTS OF THEIR APPLICATION}

\section{(C) Adekenov S. M.}

International research and production holding "Phytochemistry", Karaganda, Republic of Kazakhstan

The original antitumor preparation "Arglabin", antiatherosclerotic drug "Aterolid", hepatoprotector "Salsocollin», adaptogenic preparation «Ecdyphyt» and antiparasitic drug «Sausalin» were developed in holding «Phytochemistry» and introduced in clinic. They were developed on the basis of biologically active compounds of endemic species. Preparation "Arglabin» was tested on over 3000 oncological patients for the period 2000-2010 in the oncological centers of the far abroad and the Commonwealth of Independent States. Thus, the clinical efficiency of preparation was $76 \%$. Preparation «Arglabin» with mechanism action belongs to targeted preparations, i. e. there is not direct action on tumor cell, and on transfer path of tumor signal, namely, inhibits synthesis of farnesiltransferase. Results of I and II phases of the clinical tests of preparation «Aterolid» as hypolipidemic agent showed efficiency at treatment of 200 patients with dislocoproteinemia and atherosclerosis. «Aterolid» reduces a level of cholesterol, triglycerides and general lipids and improves a level of lipoproteins with high density more effectively than comparison preparation «Pravastatin». The clinical efficiency of hepatoprotective drug "Salsocollin" on 410 patients with chronic virus, alcoholic, toxic hepatitis, liver cirrhosis of various etiology, biliary dyskinesia and chronic noncalculous cholecystitis was proved. The cost price of course treatment with "Salsocollin" is below than widely applied preparation «Essentiale-forte». The clinical efficiency of adaptogenic preparation «Ecdyphyt» was proved at complex treatment on 450 patients with pulmonary tuberculosis. «Ecdyphyt» is well tolerated by patients, not toxic in practice, have not the expressed by-effects peculiar to anabolic steroids of testosterone row and does not influence on functionalities of adrenal cortex. The full sanitation at treatment with preparation «Sausalin» was determined by results of two phases of the clinical tri- 
als on 392 patients with verified diagnoses of lambliasis and opisthorchiasis. Thus, it testifies about its antiparasitic activity. The Karaganda pharmaceutical complex was constructed and put into operation on the basis of holding «Phytochemistry». The complex has capacity of 2 millions ampoules, 150 millions tablets, capsules and 2 millions soft dosage forms of original competitive phytopreparations.

\title{
A NEW SPIRO-SESQUITERPENOIDIC CHROMANDIONE FROM GUM AMMONIACUM WITH ACETYLCHOLINESTERASE INHIBITORY ACTIVITY
}

\author{
(C) Adhami H. R. ${ }^{1}$, Kaehlig H. ${ }^{2}$, Zehl M. ${ }^{1}$, Krenn L. ${ }^{1}$
}

${ }^{1}$ Department of Pharmacognosy, University of Vienna, Austria

${ }^{2}$ Institute of Organic Chemistry, University of Vienna, Austria
Attempts to restore cholinergic function have been considered as a rational target to improve the symptoms of Alzheimer's disease. One therapeutic option is the use of AChE inhibitors which block this key enzyme in the breakdown of acetylcholine (1). During the last decade the use of herbal medicinal preprations in dementia therapy has been studied based on traditional medicine (2). Gum ammoniacum is a gum-resin from Dorema ammoniacum D. Don which has been used in Unani and Iranian traditional medicine for several indications. A previous study showed AChE inhibitory activity for a dichloromethane extract of this resin (3). The aim of this study was the isolation and characterization of active compounds from gum ammoniacum. Extraction of the resin was performed by sonification with dichloromethane. The extract was investigated by a respective colorimetric microplate assay and the active zones were identified via TLC bioautography. Then the active compounds were isolated using several chromatographic techniques such as vacuum liquid chromatography, column chromatography and counter current chromatography. The structures of the active components were characterized by different methods such as one and two-dimension$\mathrm{al}^{1} \mathrm{H}$ and ${ }^{13} \mathrm{C}$ NMR spectroscopy (COSY, TOCSY, HSQC, HMBC, NOESY) and mass spectrometry. Two spirosesquiterpenoidic chromadiones were characterized as active components and one of them is a new compound. Their $\mathrm{IC}_{50}$ values for AChE inhibitory activity were determined by microplate assay as 77 and $100 \mu \mathrm{g} / \mathrm{ml}$. The extract was analyzed by HPLC to determine the concentration of active compounds in the extract.

References: (1) Howes MJ, Houghton PJ. 2003. Pharmacol Biochem Behav. 75: 513-527. (2) Andrade C, Sudha S, Venkataraman BV. 2000. J ECT. 16: 144-156. (3) Adhami HR, Farsam H, Krenn L. 2011. Phytother Res. 25: 1148-1152.

\section{EFFECT OF MARJORAM POWDER (ORIGANUMMAJORANA L.) AS ANTIBIOTIC GROWTH PROMOTER SUBSTITUTIONS ON PERFORMANCE AND IMMUNITY OF BROILER CHICKS}

\section{(C) Aghdam Shahryar Habib ${ }^{1}$, Akhavan Movahed Iman ${ }^{1}$, Toghyani Majid $^{2}$}

1Department of Animal Science, Shabestar Branch, Islamic Azad University, Shabestar, Iran
${ }^{2}$ Department of Animal Science, Khorasgan Branch, Islamic Azad University, Isfahan, Iran

This experiment was conducted to evaluate the effect of marjoram powder (Origanummajorana L.) as an antibiotic growth promoter substitution on performance and immune responses in broiler chicks. Three hundred day-old broiler chicks were divided randomly into four treatment groups included: control (Basal diet), antibiotic (Flavophospholipol) and marjoram powder at levels of 2 and $4 \mathrm{~g} / \mathrm{kg}$ in basal diet. Body weight, feed intake and feed conversion were recorded at 14, 28 and $46 \mathrm{~d}$. Antibody titer against Newcastle and Avian Influenza (H9 N2) viruses at $26 \mathrm{~d}$ (14 d post immunization), SRBC at $32 \mathrm{~d}$
(6 d post immunization) and heterophil to lymphocyte ratio at $42 \mathrm{~d}$ were measured. Results showed that the birds fed the 2 or $4 \mathrm{~g} / \mathrm{kg}$ marjoram powder had higher final body weight than other treatments $(P<0.05)$. Feed consumption in antibiotic group was significantly decreased. Feed conversion ratio was not affected by dietary treatments. Antibody titer against Newcastle and Influenza viruses were elevated in broiler chicks fed $4 \mathrm{~g} / \mathrm{kg}$ marjoram pow$\operatorname{der}(\mathrm{P}<0.05)$. Antibody titer against SRBC, albumin to globulin ratio and heterophil to lymphocyte ratio were not affected by dietary treatments. These results suggest that 